Supporting Information

\title{
Design and Synthesis of a Photocleavable Fluorescent Nucleotide 3'-O-Allyl-dGTP-PC-Bodipy-FL-510 as a Reversible Terminator for DNA Sequencing by Synthesis
}

Qinglin Meng ${ }^{\ddagger \ddagger}$, Dae Hyun Kim ${ }^{\dagger}$, Xiaopeng Bai ${ }^{\dagger \ddagger 9}$, Lanrong Bi ${ }^{\dagger \ddagger}$, Nicholas J. Turro ${ }^{\ddagger}$ and Jingyue $\mathrm{Ju}^{\dagger+*}$

${ }^{\dagger}$ Columbia Genome Center, Columbia University College of Physicians and Surgeons, New York, NY 10032; and Department of ${ }^{\ddagger}$ Chemical Engineering, ${ }^{5}$ Chemistry, and ${ }^{8}$ Biomedical Engineering, Columbia University, New York, NY 10027

E-mail: ju@genomecenter.columbia.edu 


\section{Table of Contents:}

$\begin{array}{ll}\text { Materials and General Procedures } & \text { S2 }\end{array}$

${ }^{1} \mathrm{H}$ NMR and ${ }^{13} \mathrm{C}$ NMR spectra for $2 \quad$ S3-S4

${ }^{1} \mathrm{H}$ NMR and ${ }^{13} \mathrm{C}$ NMR spectra for $3 \quad$ S5-S6

${ }^{1} \mathrm{H}$ NMR and ${ }^{13} \mathrm{C}$ NMR spectra for $4 \quad$ S7-S8

${ }^{1} \mathrm{H}$ NMR and ${ }^{13} \mathrm{C}$ NMR spectra for $5 \quad$ S9-S10

${ }^{1} \mathrm{H}$ NMR and ${ }^{13} \mathrm{C}$ NMR spectra for $6 \quad$ S11-S12

${ }^{1} \mathrm{H}$ NMR and ${ }^{13} \mathrm{C}$ NMR spectra for $7 \quad$ S13-S14

${ }^{1} \mathrm{H}$ NMR and ${ }^{13} \mathrm{C}$ NMR spectra for $8 \quad$ S15-S16

${ }^{1} \mathrm{H}$ NMR and ${ }^{31} \mathrm{P}$ NMR spectra for $9 \quad$ S17-S18

Materials and General Procedures. ${ }^{1} \mathrm{H}$ NMR spectra were recorded on a Brucker DPX-400 $(400 \mathrm{MHz})$ spectrometer and are reported in ppm from $\mathrm{CD}_{3} \mathrm{OD}$ or DMSO-d6 internal standard (3.31 or 2.50 ppm respectively). Data are reported as follows: $(\mathrm{s}=$ singlet, $\mathrm{d}=$ doublet, $\mathrm{t}=$ triplet, $\mathrm{q}=$ quartet, $\mathrm{m}=$ multiplet, $\mathrm{dd}=$ doublet of doublets, $\mathrm{ddd}=$ doublet of doublets of doublets; coupling constant(s) in $\mathrm{Hz}$; integration). Proton decoupled ${ }^{13} \mathrm{C}$ NMR spectra were recorded on a Brucker DPX-400 (100 MHz) spectrometer and are reported in ppm from $\mathrm{CD}_{3} \mathrm{OD}$, DMSO-d6, or $\mathrm{CDCl}_{3}$ internal standard $\left(49.0,39.5\right.$, or $77.0 \mathrm{ppm}$ respectively). Proton decoupled ${ }^{31} \mathrm{P} \mathrm{NMR}$ spectrum was recorded on a Brucker DPX-300 (121.4 MHz) spectrometer without calibration. High Resolution Mass Spectra (HRMS) were obtained on a JEOL JMS HX 110A mass spectrometer. Mass measurement of DNA was made on a DE MALDI-TOF mass spectrometer. Photolysis was performed by using a Spectra Physics GCR-150-30 Nd-yttrium/aluminum garnet laser that generates light pulses at $355 \mathrm{~nm}$. Compound 1 was purchased from Berry \& Associates (Dexter, MI). $9^{\circ} \mathrm{N}$ polymerase (exo-) A485L/Y409V was generously provided by New England Biolabs. 


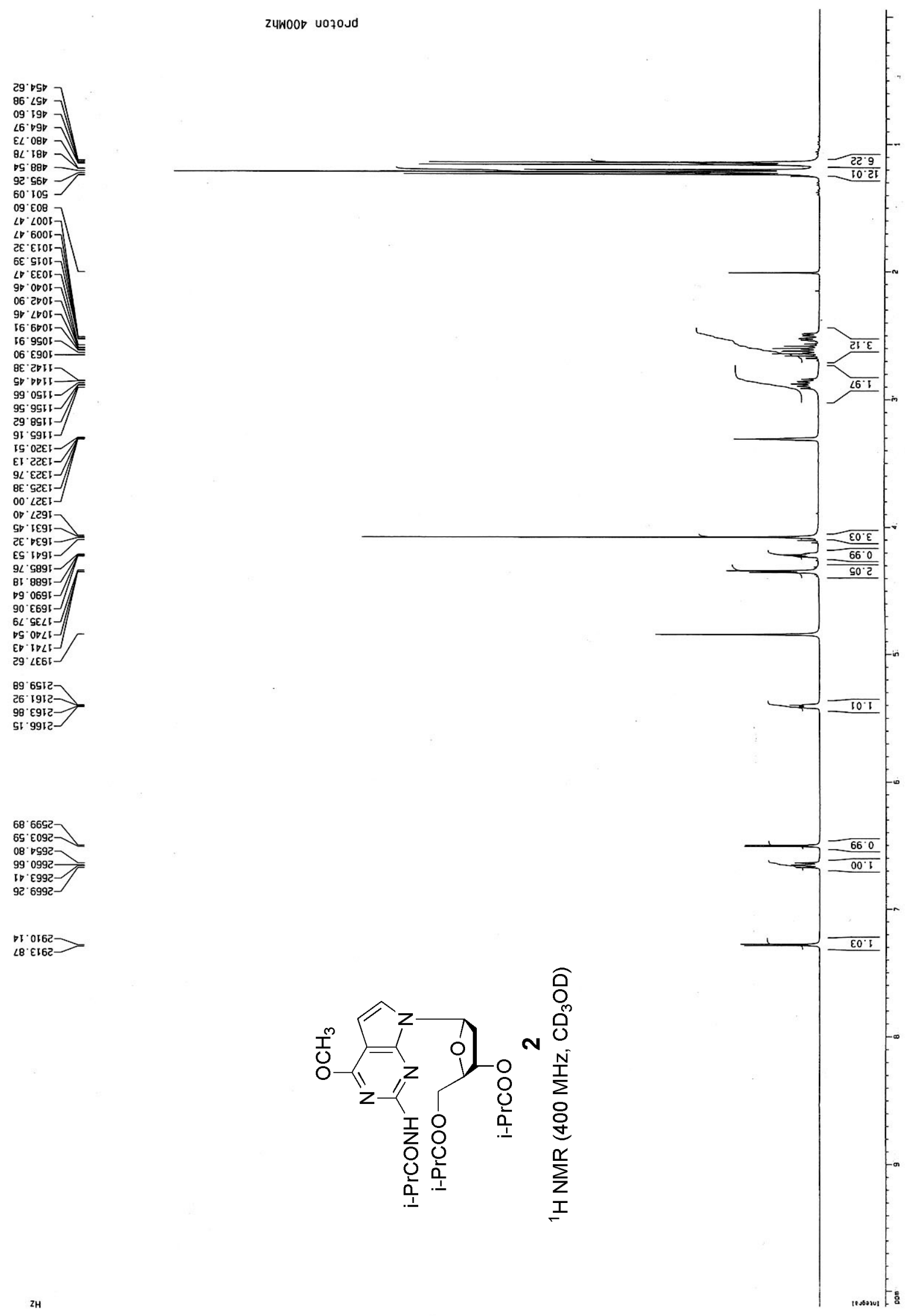




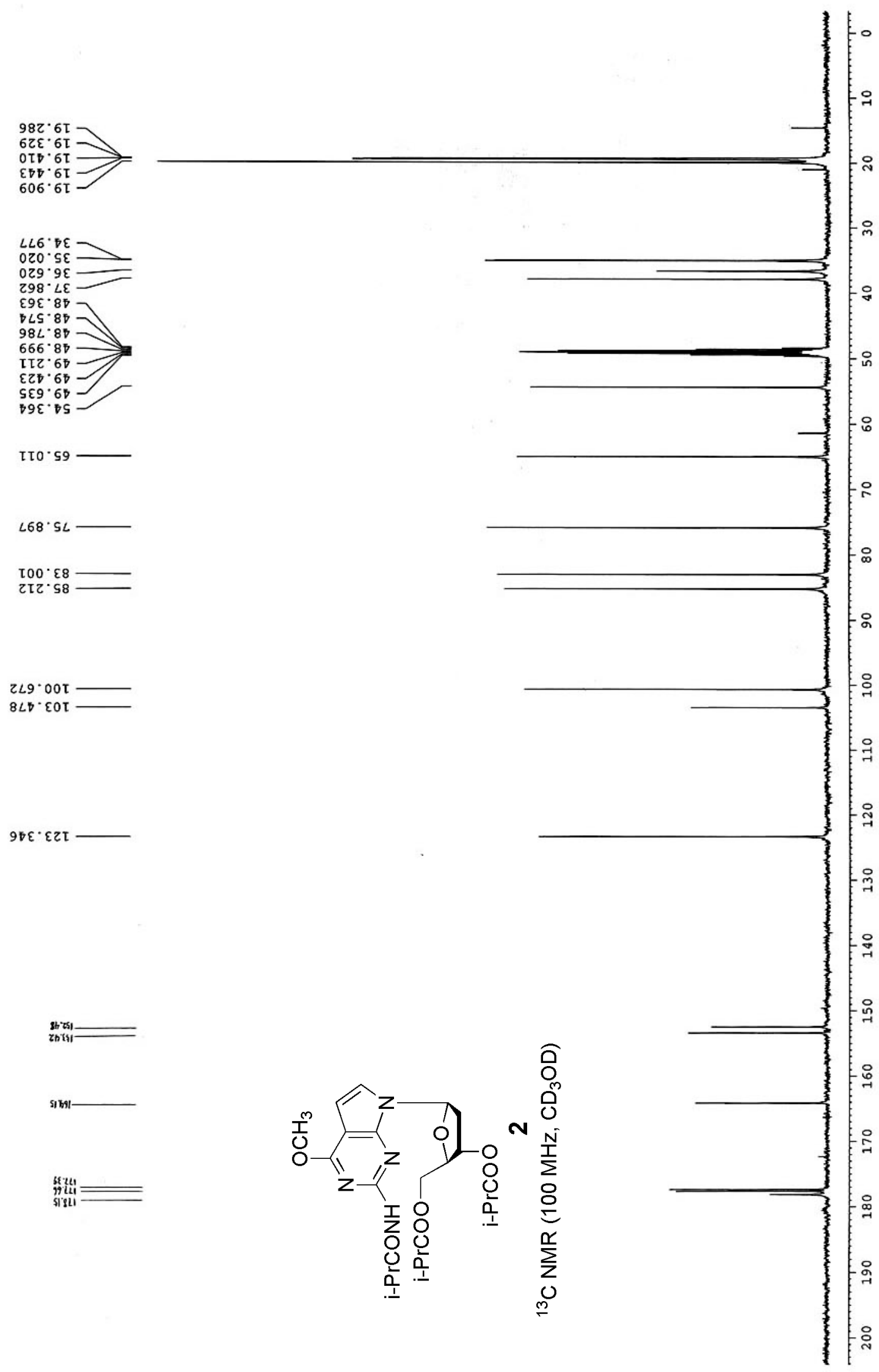




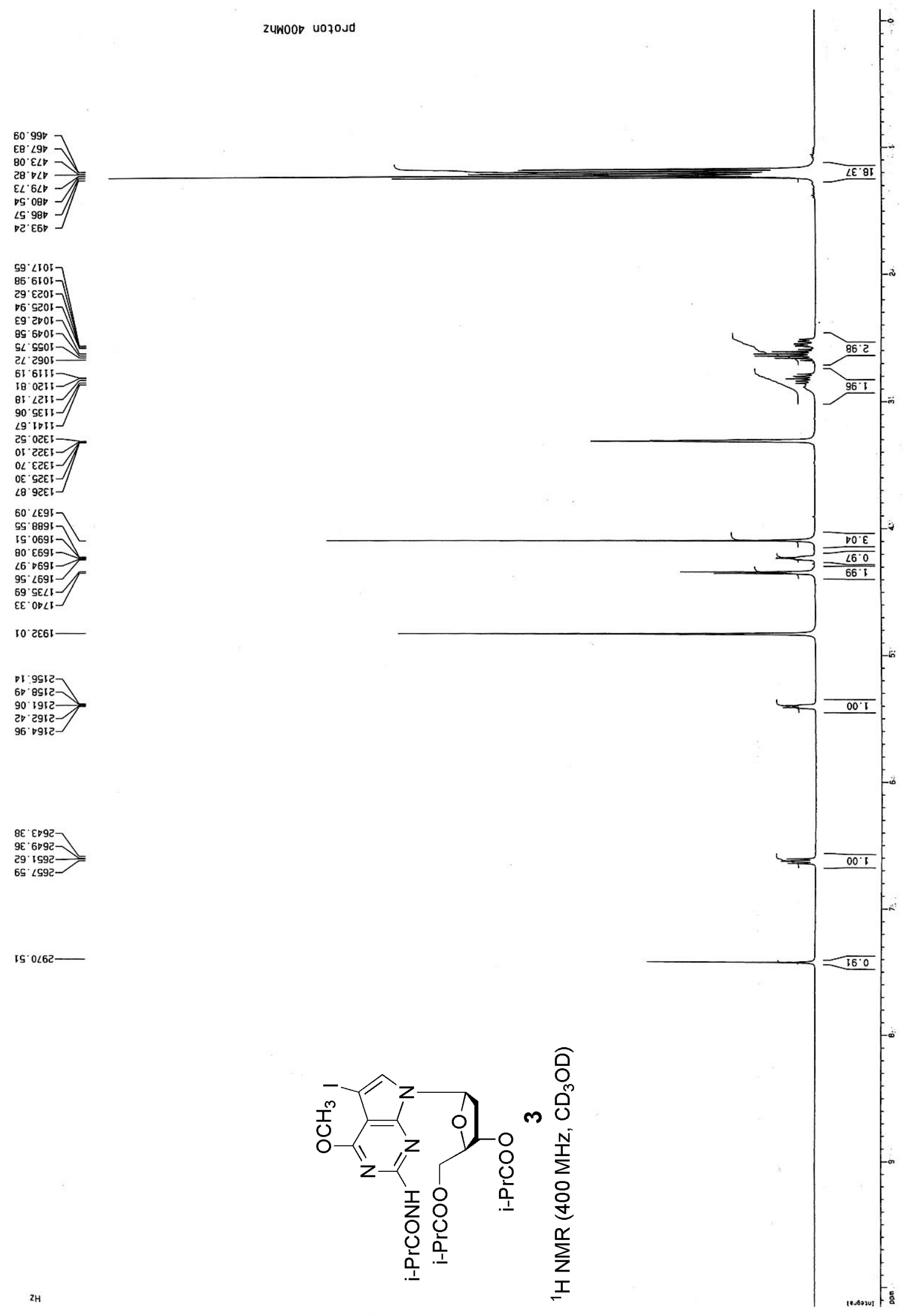




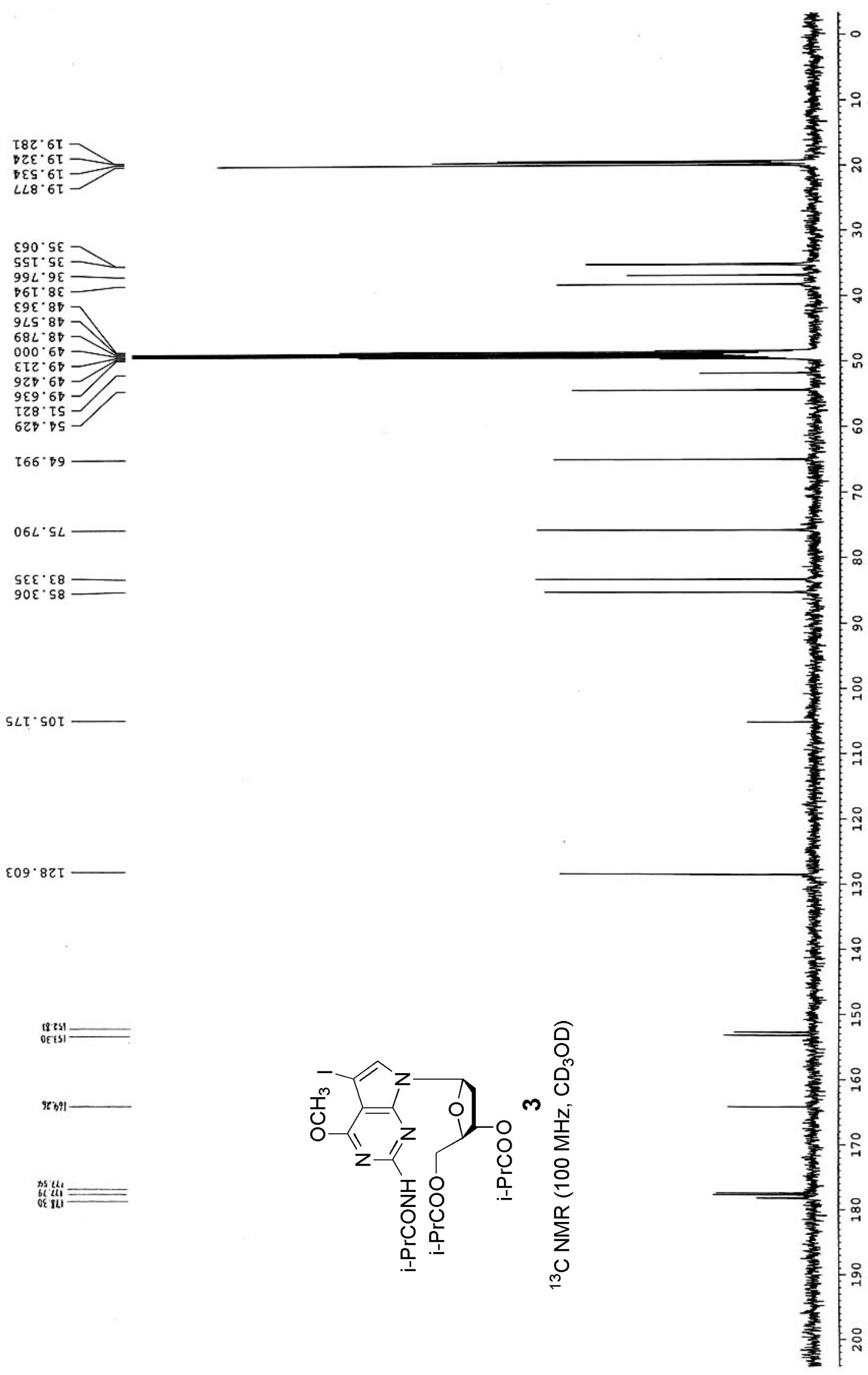




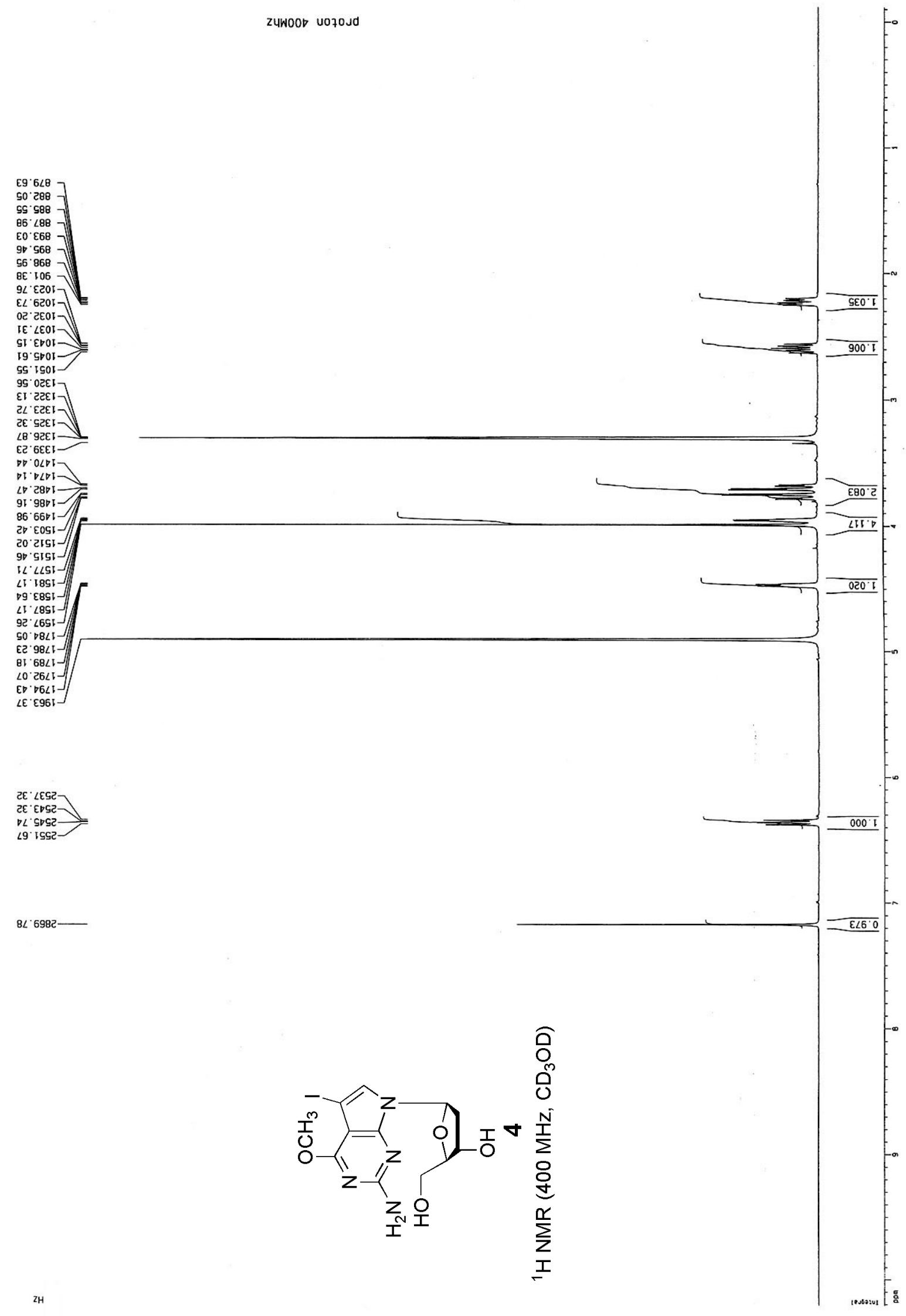




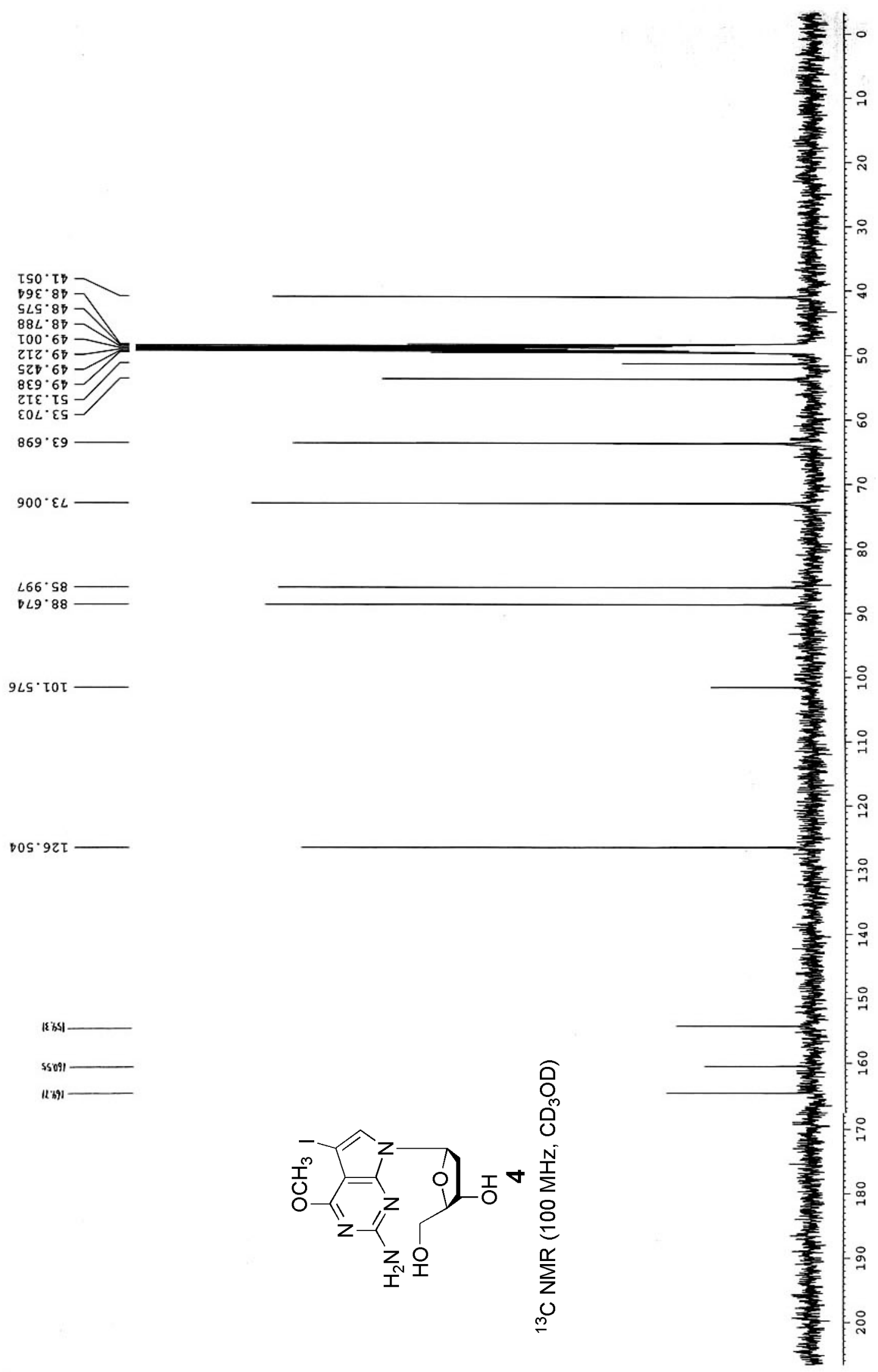




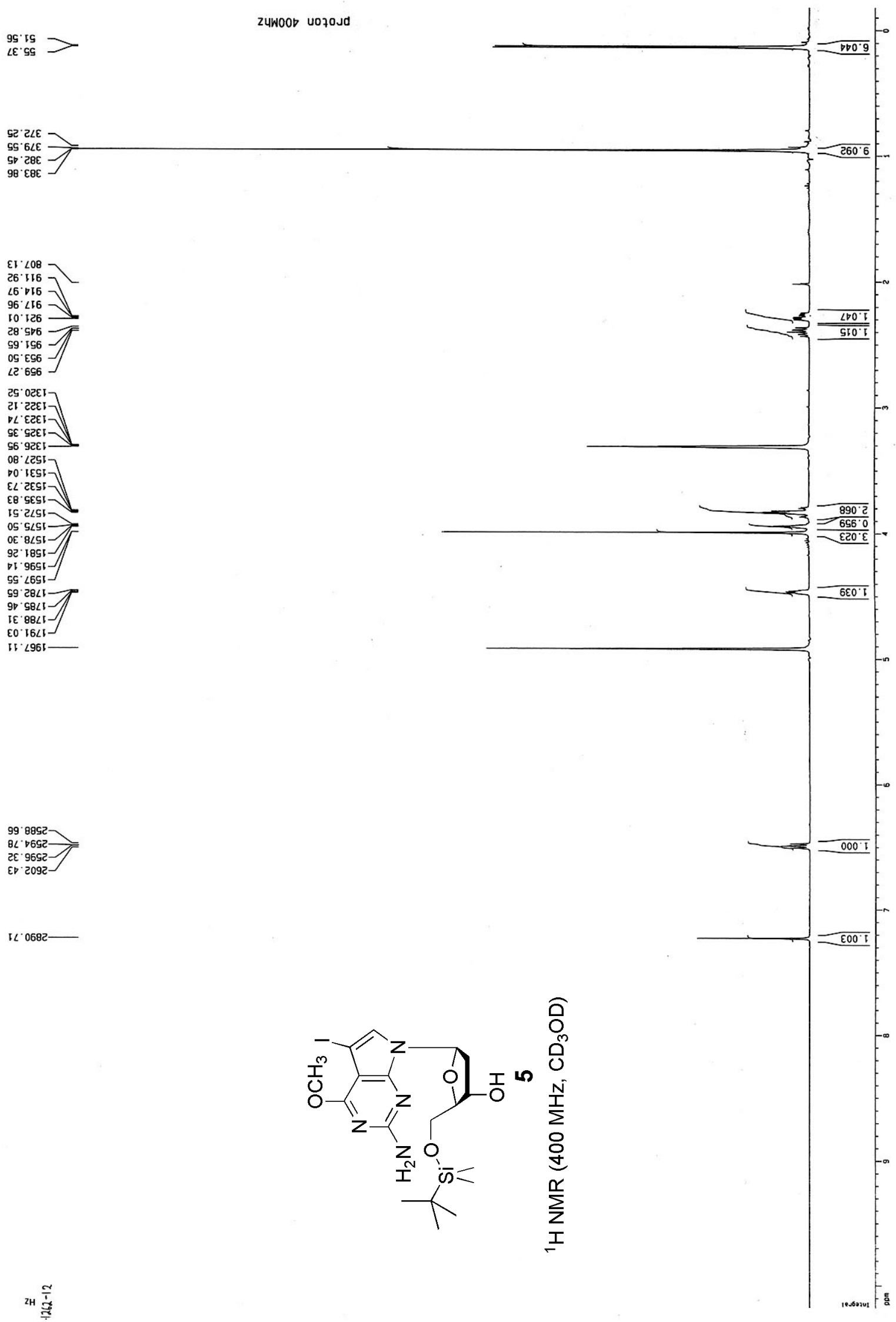




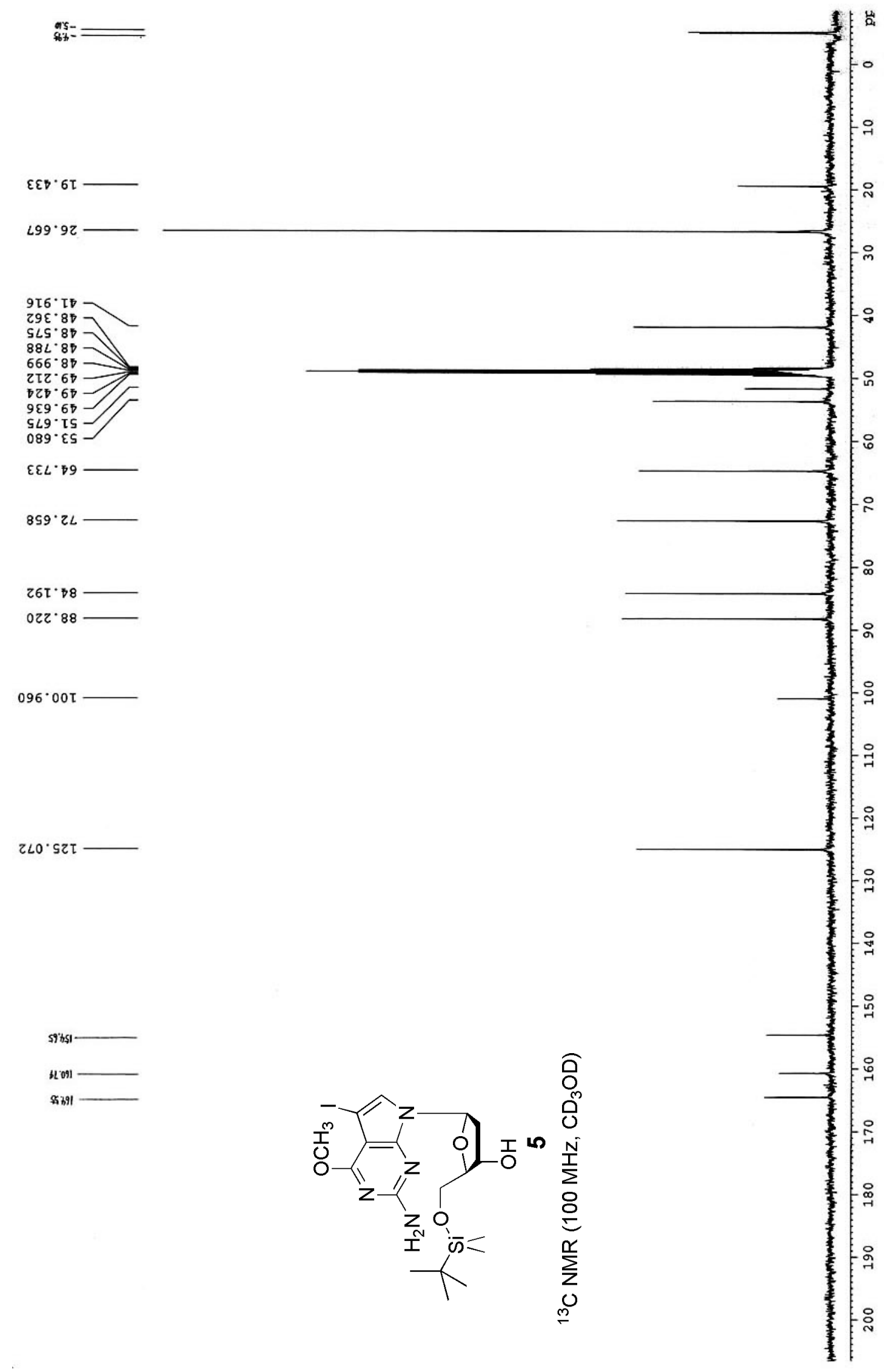




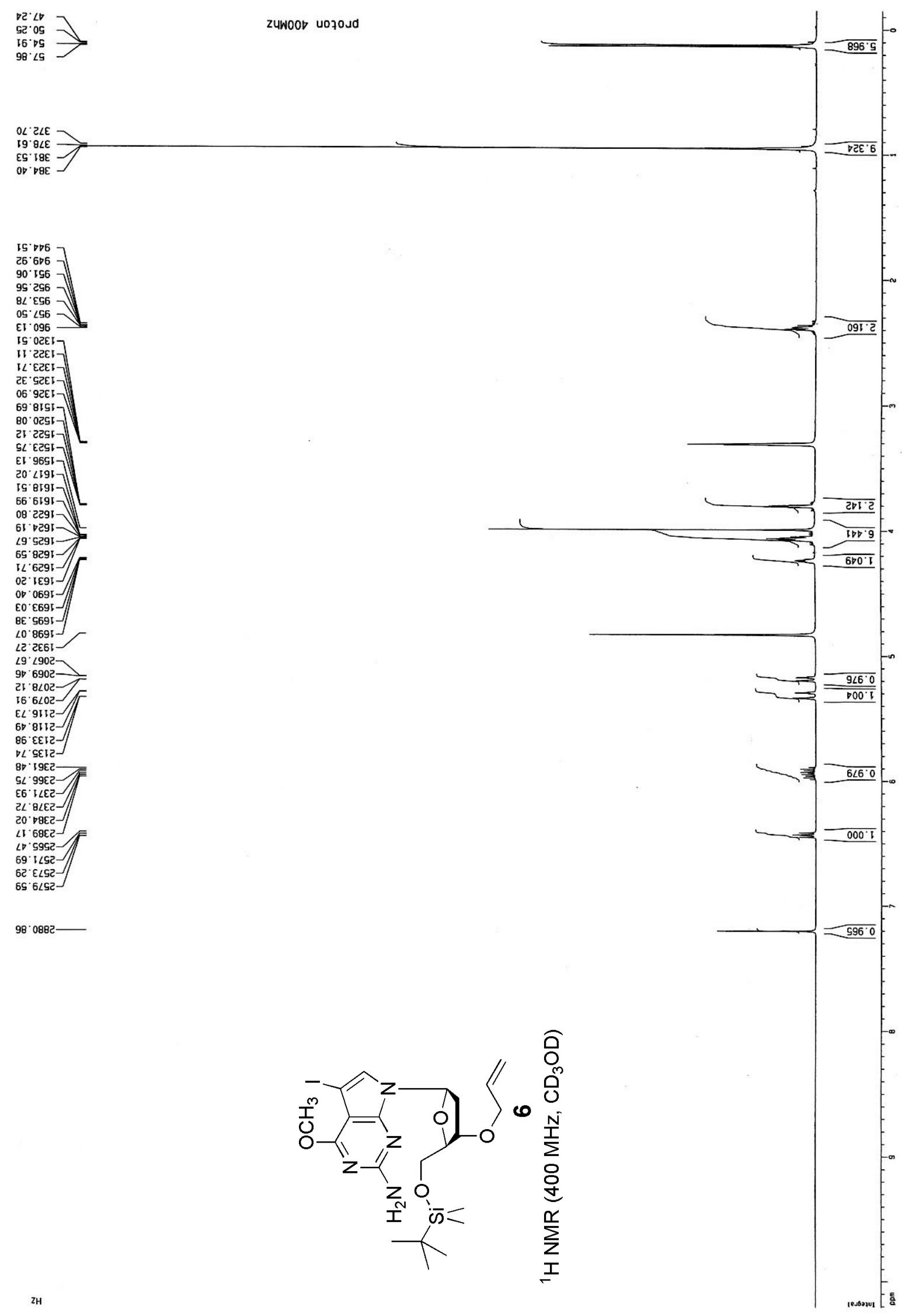




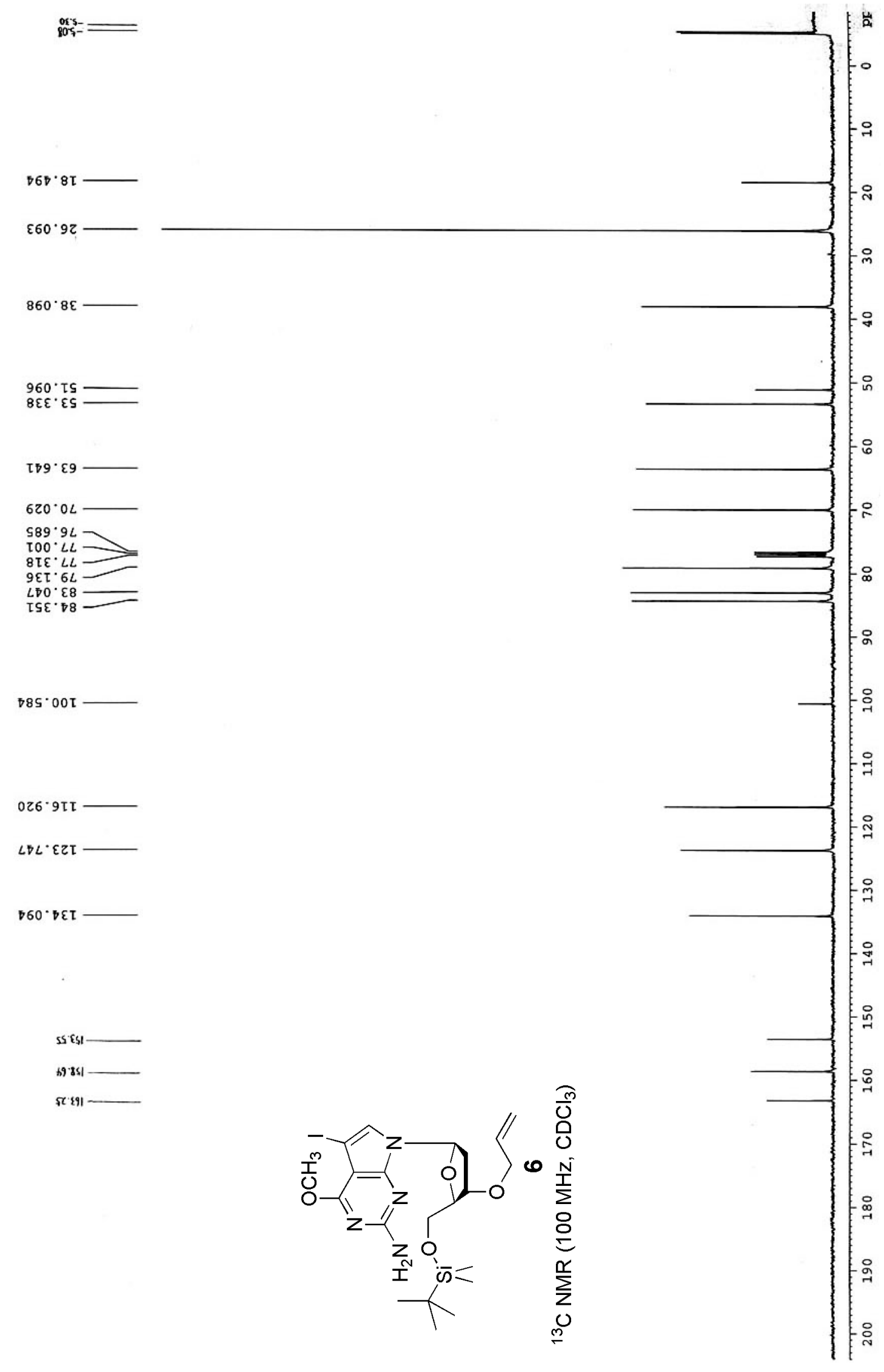




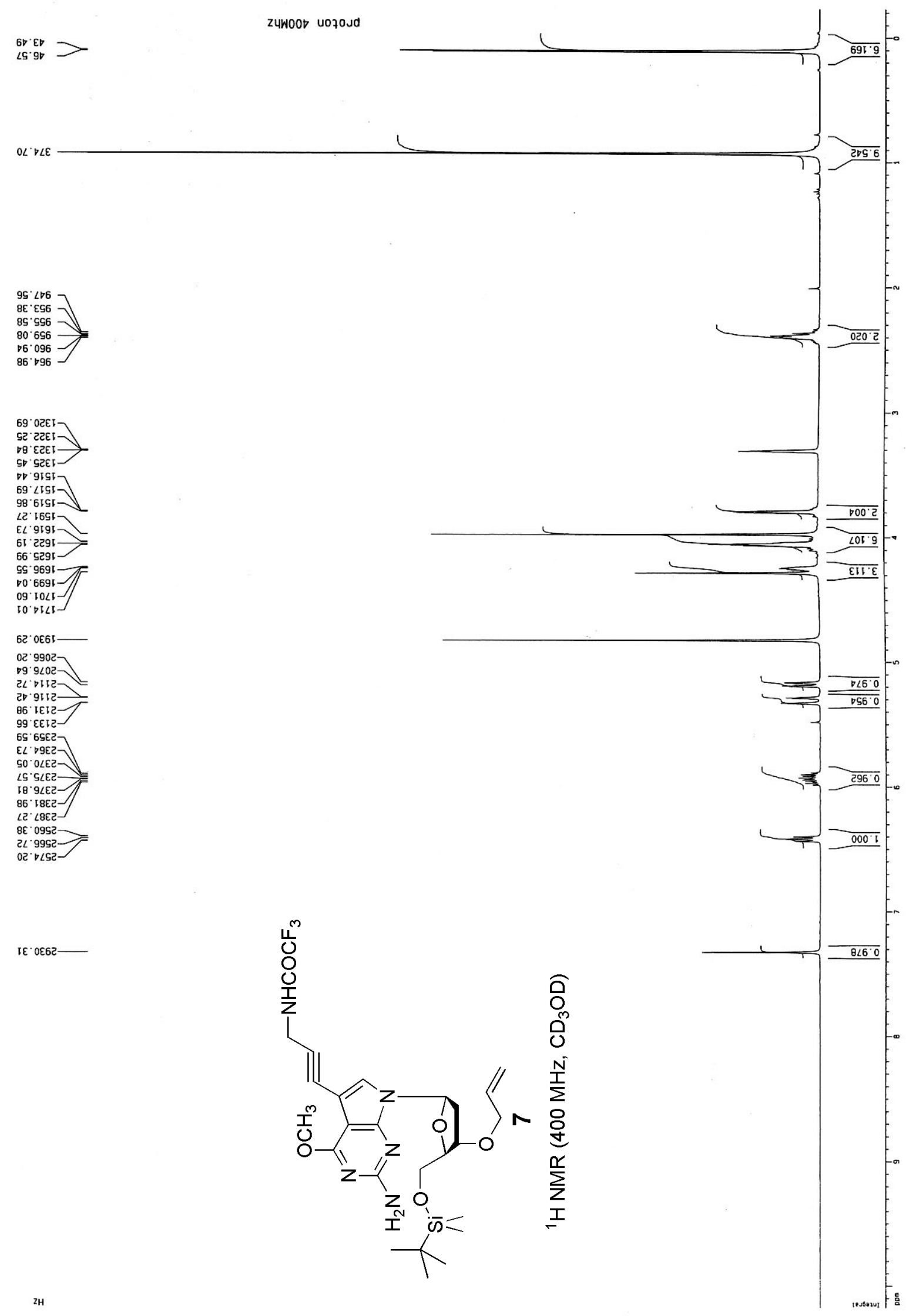




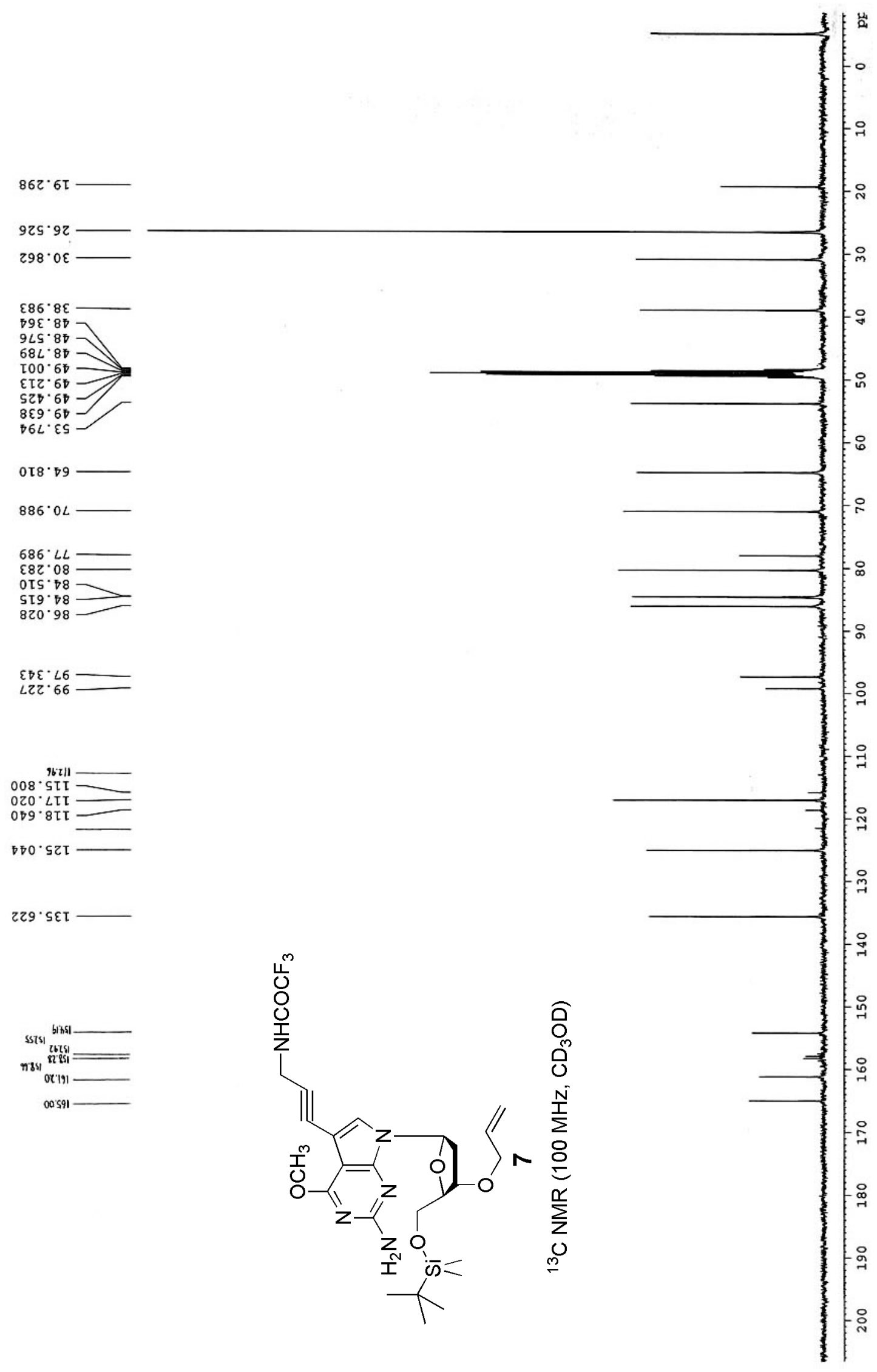




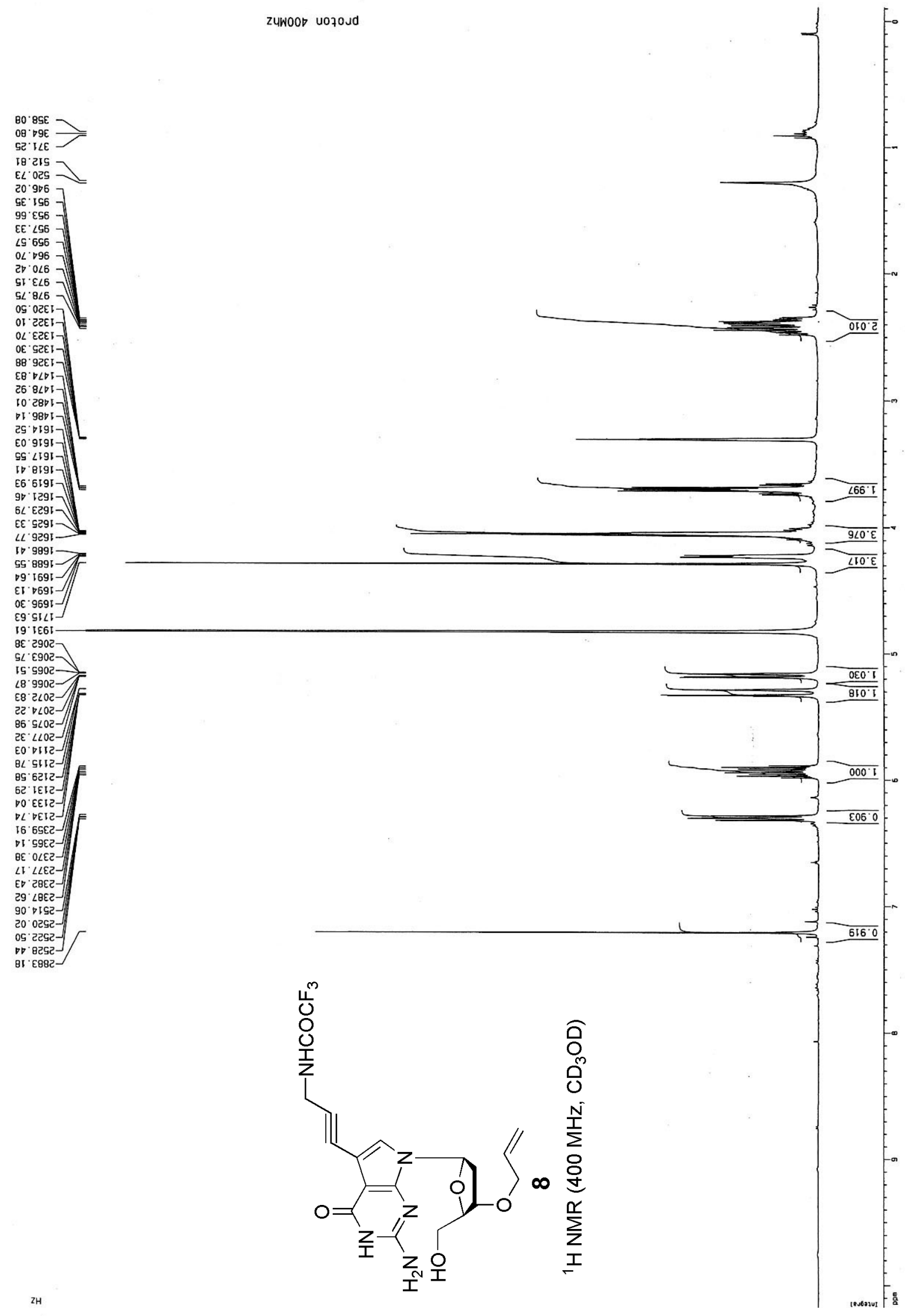




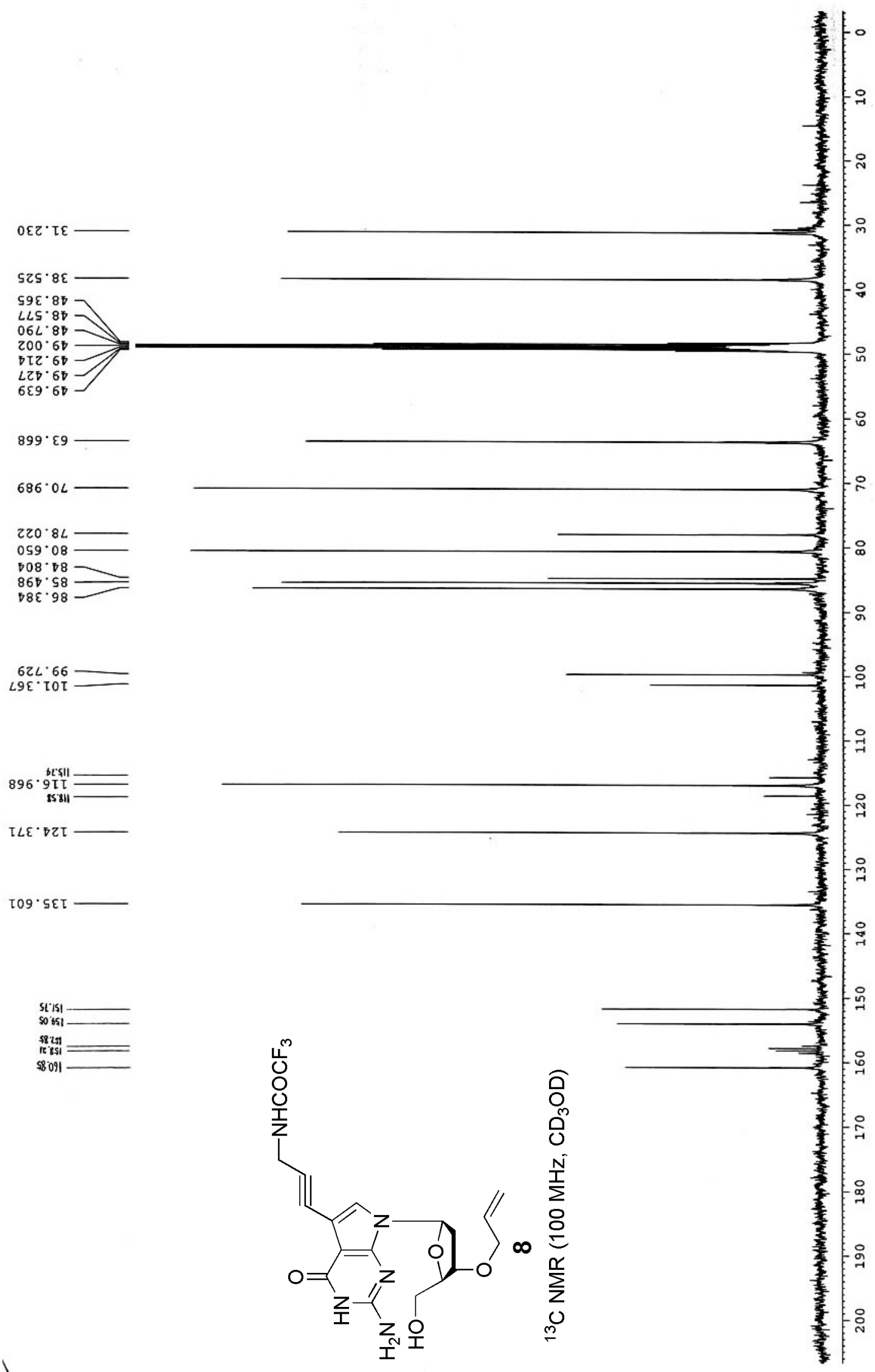




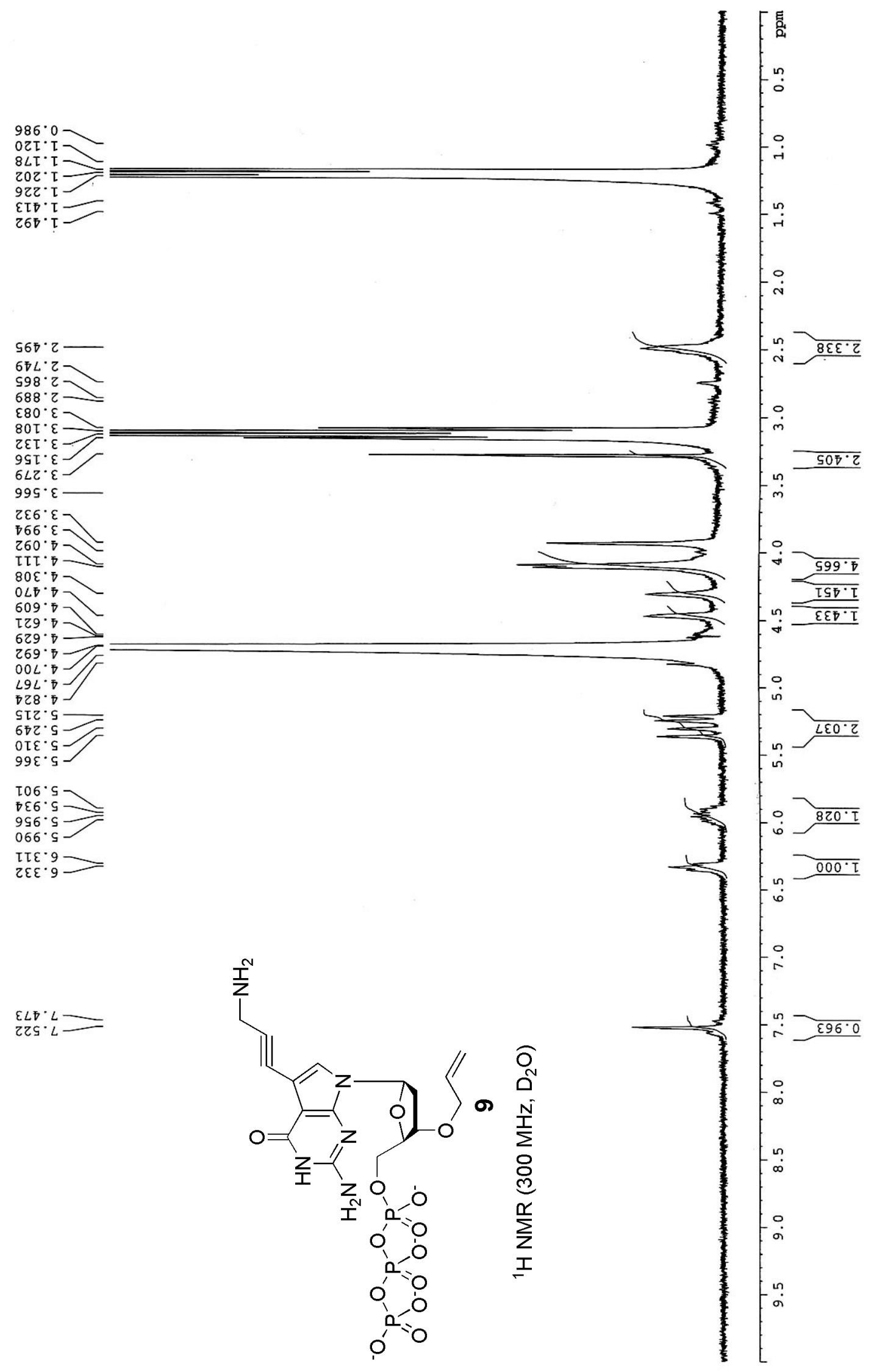




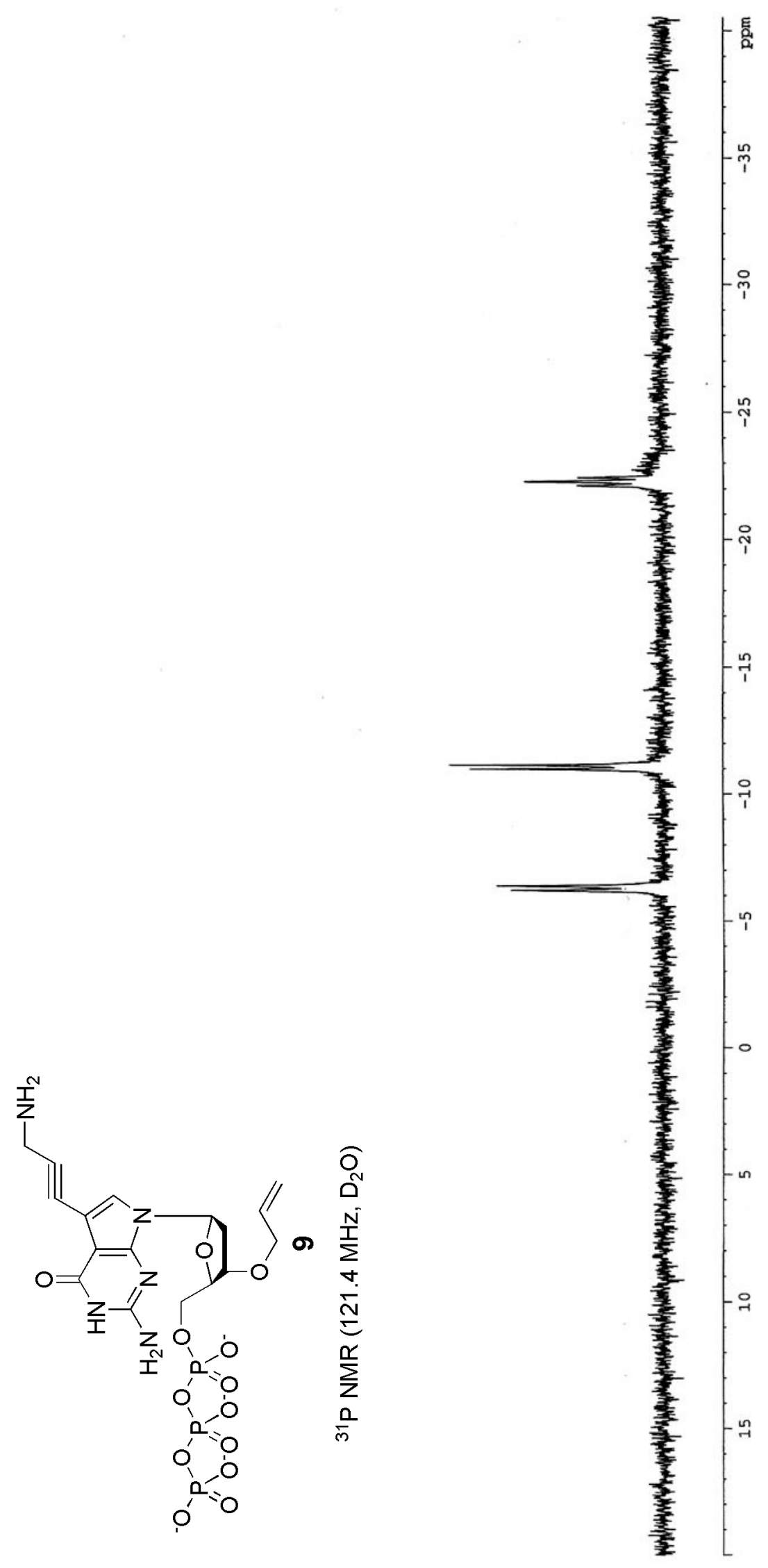

